\title{
E-Cigarette: A New Tobacco Product for Schoolchildren in Paris
}

\author{
Bertrand Dautzenberg ${ }^{1,2,3,4}$, Pierre Birkui ${ }^{1}$, Maryvonne Noël ${ }^{5}$, \\ Johanna Dorsett ${ }^{2}$, Monique Osman ${ }^{1,2}$, Marie-Dominique Dautzenberg ${ }^{2,6,7}$ \\ ${ }^{1}$ Paris Sans Tabac (PST), Paris, France \\ ${ }^{2}$ Office Français de Prévention du Tabagisme (OFT), Paris, France \\ ${ }^{3}$ Groupe Hospitalier Pitié-Salpêtrière (APHP), Paris, France \\ ${ }^{4}$ Université Pierre et Marie Curie, Paris, France \\ ${ }^{5}$ Rectorat de l'Académie de Paris, Paris, France \\ ${ }^{6}$ Hôpital Necker Enfants-Malades, Paris, France \\ ${ }^{7}$ Université René Descartes, Paris, France \\ Email: bdautz@gmail.fr
}

Received January 13, 2013; revised February 3, 2013; accepted February 10, 2013

\begin{abstract}
Objectives: To explore if the dramatic decrease in price of e-cigarette has transformed this new product into a product used for tobacco initiation among a teenage population. Methods: The authors added a question in 2012 on e-cigarette in the yearly survey on tobacco consumption in Paris schoolchildren. The study is conducted on a randomly selected sample from 2\% of classes since 1991. Results: 277 (8.1\%) of the 3409 schoolchildren studied (including 575 non responders to this question) reported having had an experience with e-cigarette. Experimentation rate is $6.4 \%$ among the 12 - 14-year-old, $11.8 \%$ among the 15 - 16-year-old and $9 \%$ among the 17 -year-old schoolchildren. Among the 12 - $14-$ year-old schoolchildren, $64.4 \%$ of e-cigarette experimentation was by non-smokers. Of the 17 -year-old teenagers who had used e-cigarettes, $12.4 \%$ were non-smokers. For the whole population, 33.2\% of those having tried e-cigarette are non-smoker, $22.7 \%$ occasional smoker, $3.6 \%$ ex-smoker and $40.4 \%$ daily smoker. Those who experiment cannabis, shisha or binge-drinking are more frequently users of e-cigarette. In the smoker group, there is an inverse trend of relationship between the readiness to quit tobacco and the rate of use of e-cigarette. Conclusion: For teenager's, e-cigarettes have become not a product to aid quit tobacco but a product for experimentation and initiation of cigarette use. Regulation is urgently needed to control the emergent use of this new tobacco product by children.
\end{abstract}

Keywords: E-Cigarettes; Teenagers; Tobacco Initiation; Epidemiologic Study

\section{Introduction}

The principle of the e-cigarette was born to an idea by Herbert A. Gilbert, who on 1965 patented a device that shares the main characteristics of e-cigarettes [1]. The history of e-cigarette then restarted at the beginning of XXI century. The invention of e-cigarettes is attributed to Hon Lik, Chinese pharmacist [2]. The first prototype of electronic cigarette uses a lithium battery to produce energy to vaporize glycerol and a nicotine solution through a piezoelectric device. The beginning of each puff is controlled by an on demand valve. The ultrasonic production of aerosol has since been replaced by a heating element in commercialised e-cigarettes. The device was first introduced to the Chinese domestic market in May 2004 as a support for smoking cessation. Then export began in 2005-2006, before an international patent in 2007 [1]. The efficacy of e-cigarettes for tobacco cessation has not been shown [3]. Many health authorities refuse to say that this product is beneficial for smoking cessation in the absence of studies. More recently this product has been sold for use where smoking is banned [4], but many site managers of private or public places, such as airlines companies [5], have taken the initiative to ban indoor ecigarette use. Now this product is most often sold as a new, cool alternative to smoking. E-cigarette is cheap because they are not taxed as tobacco products and because recently new disposable e-cigarettes has been marketed. This cheap product potentially provides a gateway for tobacco use in teenagers due to a price decrease from 60 $100 €$ to less than $6-10 €$. This present study was conducted to see whether the concern that e-cigarettes has become a new product for tobacco initiation use in teenagers is justified or not. We had introduced a question about the e-cigarette in the yearly cross-sectional survey conducted by Paris Sans Tabac [6]. 


\section{Methods}

A cross-sectional survey is conducted yearly with a one page questionnaire by Paris Sans Tabac on 2\% of students randomly selected by class provided a representative sample of the 188,000 schoolchildren of Paris. Anonymous questionnaires were distributed and collected with the help of Paris School authorities. The study provides yearly data on smoking among Parisian schoolchildren with the same methodology since 1991. A question about e-cigarettes was added in 2012, like one we had added a question about shisha ten years ago. This question is "have you ever used an e-cigarette?"

The non-independence between smoking status and experimentation of e-cigarette has been assessed by Chi-2 test. The relative risk (RR) with $95 \%$ confidence interval was used to compare experimentation of e-cigarette according to the other use of substances.

\section{Results}

A total of 3409 schoolchildren from 12 to 19 years old were questioned during the first quarter of 2012. 49.5\% were girls. The mean age of this population is 15.3 -years. In this population the percentage of occasional tobacco smoker's increases from $6 \%$ to $12 \%$ between 12 and 14 year-old, then remains close to $12 \%$. The rate of daily cigarette smoking increases from 5\% for 13-year-old schoolchildren to $25 \%$ for 18 -year-old schoolchildren.

A total of 277 teenagers from the study report to have used e-cigarettes, 2557 never used and 575 provide no answer to this question (83.2\% answer rate). Among the schoolchildren who have ever used e-cigarettes, 47 report to have never used regular cigarettes $(18.6 \%$ of ever e-cigarette users).

The percentage of teenagers reporting experimentation of e-cigarettes is $6.4 \%$ for 12 - 14-year-old schoolchildren, $11.8 \%$ among 15 - 16-year-olds, $19 \%$ among 17 year-old and drops down to $9.3 \%$ for the 18 - 19-yearold schoolchildren. Until the age of 17 years, more girls have experienced e-cigarettes than boys, with a maximum experimentation rate at age 17 for girls (23.2\%) (Figure 1).

The experimentation rate of e-cigarette changes according to smoking status (Chi-2 test, $P<0.05$ ): $4.4 \%$ of non-smokers, $16.4 \%$ of occasional smokers, $19.6 \%$ of exsmokers and $33.4 \%$ of regular smokers have tried using e-cigarettes. But as smoking regular cigarettes is low in 12 - 14 year old schoolchildren, $64.4 \%$ of those who tried e-cigarette in these young teenagers are not regular cigarette smokers.

Among the 421 daily smoking teenagers, 112 had tried e-cigarettes $(26.7 \%)$. The rate of e-cigarette users tend to be lower for those who plan to quit now (26\%), or in the next 6-month period (25\%), compare for those who plan

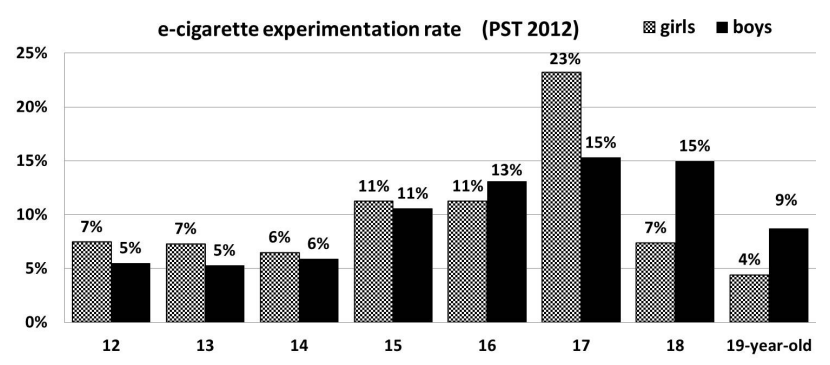

Figure 1. Percentage prevalence of the teenagers, separately among girls and boys and age of those who had experimented on e-cigarettes assessed through the question: "have you ever used an e-cigarette?” of the PST 2012 survey on 3409 Parisian schoolchildren.

to quit tobacco later (37\%) or don't plan to quit smoking at all (33\%) An inverse relationship trend exists between ever use of e-cigarette and intent to quit regular smoking. (RR 1.58; IC 95\%: 0.89 - 2.80).

Experimentation of e-cigarette is more frequent among a 12 - 15-year-old teenage population who have ever used shisha (RR $=6.75$; IC 95\%: $4.84-9.41)$ and much more frequent in the 16 - 19-year-old population who have ever used shisha $(\mathrm{RR}=14.81$; IC 95\%: 7.54 29.06).

Experimentation of e-cigarettes is more frequent in the 12 - 15-year-old teenage population who had ever used cannabis (RR $=5.52$; IC 95\%: $4.15-7.35)$ and as the 16 - 19 year old population $(\mathrm{RR}=9.09$; IC 95\%: 6.12 13.50).

Experimentation of e-cigarette is more frequent in 12 15 -year-old teenagers who had experimented more than 4 times with more than 3 alcohol glasses the same day (RR $=8.60$; (IC 95\%: $5.71-12.96)$ as in the $16-19$ year old population $(\mathrm{RR}=3.44$; IC 95\%: $2.94-4.03)$.

\section{Discussion}

This is one of the first studies to our knowledge which reports data on use of e-cigarettes in European teenagers. In our study, e-cigarettes appeared recently on the French market and rapidly became a familiar product to young Parisian schoolchildren. This 12 - 15-year-old teenager's school population produces a good picture of the general population of Paris. For the 16 - 19-year-old teenagers, the sample is representative of Paris school population, but not of the general population because some teenagers leave school then they are 16-year-old and many 16 19-year-old teenagers from suburbs of Paris come in Paris to follow the last years of school. The rate of cannabis use or experimentation of binge-drinking among teenagers is quite different according to gender, but the experimentation of e-cigarette is quite equally distributed in both genders. Users are mostly 14 - 17-year-old (10.6\% in girls vs. $9.1 \%$ in boys (NS)). The older teenagers (18 19-year-old) had a lower rate of ever use of e-cigarette, 
probably because they were not exposed to e-cigarette before initiation of regular-cigarette-smoking habit, at a time where disposable e-cigarette were not available. The experiment tobacco cigarette or shisha is mainly $14-17$ year-old teenagers in the PST studies. Our data are compatible with the same age of experimentation for e-cigarette.

In our study there is a clear link between experimentation of cannabis, shisha or binge-drinking and the experimentation of e-cigarette among a population of teenagers. There is also a strong link with the tobacco smoking status, but there is no positive link in our teenage smokers between ever use of e-cigarette and the intent to quit tobacco. In our study the trend was inversed. E-cigarette is used by teenagers in Paris to experiment new sensations, not to decrease tobacco use. E-cigarette is clearly a product of initiation to cigarette, not a product for tobacco cessation in this teenager population.

Four studies are available on the use of e-cigarettes from Medline research in November 2012.

A consumer-based mail-in survey [7] was completed in the US by 10587 adults ( $\geq 18$-year-old) in 2009 and 10,328 adults in 2010. Ever use more than quadrupled from $2009(0.6 \%)$ to $2010(2.7 \%)$. Use of e-cigarette was most common among women and those with lower education. Current tobacco users, as in our study, were most likely to try e-cigarettes. However, current smokers who had tried e-cigarettes did not say they planned to quit smoking more often than smokers who had never tried them, as in our study in teenagers.

A study among US adults report data from 2 surveys conducted in 2010 [8]: a national online study ( $n=2$ 649 ) and the Legacy Longitudinal Smoker Cohort $(n=$ 3658) who report another online survey. The use of e-cigarette was higher among current smokers (11.4\%, 95\% CI: 9.3 - 14.0) than in former smokers $(2.0 \%, 95 \% \mathrm{CI}$ : $1.0-3.8)$ or in never-smokers $(0.8 \%, 95 \%$ CI: 0.35 1.7).

A study conducted in Korea used the data from the 2008 Health Promotion Fund Project [9] those who had tried e-cigarettes among adolescents in five schools in Korea. Overall, 444 (10.2\%) students responded as having seen or heard of e-cigarettes. Only twenty-two students who had seen this product reported as having used an e-cigarette $(0.5 \%$ of the student study population). The contact routes of information on e-cigarettes were the Internet $(249,46.4 \%)$, friends $(150,27.9 \%)$, television $(59,11.0 \%)$, books $(50,9.3 \%)$, and others $(29$, $5.4 \%$ ). This data had been conducted before the availability of disposable e-cigarettes.

More recently in Poland a large survey conducted in high schools en 2011 [10] reported that $23.5 \%$ of students aged 15 to 19 had ever use e-cigarettes and that $8.2 \%$ had done so within the previous 30 days. It is in the same range but higher than reported among Parisian students in our study. As in our study, in Poland a significant number of never smoker's students reported ever used of e-cigarettes $(3.2 \%)$.

Compared to publish studies, our 2012 study reports in teenagers an experimentation ten times higher than the experimentation rate of Korean students in 2008, two times higher than in the US adult population in 2010 , but lower than the polish study. The use of e-cigarettes in non-regular cigarette smokers and the general consumption in our teenager study are high. In adults, a US study shows no link with intent to stop tobacco. In our teenager study there is an inverse correlation: daily smoking teenagers who plan to quit soon are less often ever users of e-cigarettes.

E-cigarette ever use is in high expansion in teenagers. The majority of experimentation of e-cigarette in 12 - 14year-old occurs in non-smokers. E-cigarette ever use in smokers who plan to quit soon was less than in those who don't plan to quit. E-cigarette is used as other new tobacco products. To prevent this initiation and this use as an initiation tobacco product, we recommend regulating e-cigarettes as it is done for other tobacco products (or medicine), to prohibit any promotion and sale in shops or on the Internet to teenagers under 18 years old. The new project of EU directive on tobacco product [11] opens a room with article 18 for regulation of product other than tobacco who deliver nicotine. The prevention of use of e-cigarette by teenagers is need in this new regulation.

\section{Acknowledgements}

This work was conducted with help of Paris school authorities (Rectorat de l'Académie de Paris); PST is supported by the Paris section of National Insurance (CPAM) and OFT receives a support of the French Ministry of health (DGS) to assess e-cigarettes.

\section{REFERENCES}

[1] http://www.google.com/patents?id=RjlUAAAAEBAJ\&pr itsec $=$ abstract \&zoom $=4 \&$ source $=$ gbs_overview_r\&cad $=0$ $\# \mathrm{v}=$ onepage \&q\&f$=$ false

[2] Kcancer, "2010 Kcancer Hero Mr Hon Lik,” 2010. http://www.prlog.org/10588774-hon-lik-2010-kcancer-he ro-nominee.html

[3] R. Polosa, P. Caponnetto, J. B. Morjaria, G. Papale, D. Campagna and C. Russo, "Effect of an Electronic Nicotine Delivery Device (E-Cigarette) on Smoking Reduction and Cessation: A Prospective 6-Month Pilot Study," BMC Public Health, Vol. 11. No. 786, 2011, pp. 1-12.

[4] M. Laugesen, "Nicotine Electronic Cigarette Sales Are Permitted under the Smokefree Environments Act," The New Zealand Medical Journal, Vol. 123, No. 1308, 2010, pp. 103-105. 
[5] International Air Transport Association, "Electronic Cigarettes" 2012.

https://www.iata.org/whatwedo/safety/Documents/guidan ce-electronic-cigarettes.pdf

[6] B. Dautzenberg, P. Birkui, J. Rubal, L. R. França and M. P. Duflot, "Decrease in Smoking by Parisians Students after the Launch and Implementation of a National Cancer Prevention Plan," Santé Publique, Vol. 17, No 4, 2005, pp. 519-530. doi:10.3917/spub.054.0519

[7] A. K. Regan, G. Promoff, S. R. Dube and R. Arrazola, "Electronic Nicotine Delivery Systems: Adult Use and Awareness of the 'E-Cigarette' in the USA," Tobacco Control, Vol. 22, No. 1, 2013, pp. 19-23.

doi:10.1136/tobaccocontrol-2011-050044

[8] J. L. Pearson, A. Richardson, R. S. Niaura, D. M. Vallone and D. B. Abrams, "E-Cigarette Awareness, Use, and Harm Perceptions in US Adults," American Journal of Public Health, Vol. 102, No. 9, 2012, pp. 1758-1766.
doi:10.2105/AJPH.2011.300526

[9] J. H. Cho, E. Shin and S. S. Moon, "Electronic-Cigarette Smoking Experience among Adolescents," Journal of Adolescent Health, Vol. 49, No. 5, 2011, pp. 542-546. doi:10.1016/j.jadohealth.2011.08.001

[10] M. L. Goniewicz and W. Zielmska-Danch, "Electronic Cigarette Use among Teenagers and Young Adults in Poland," Pediatrics, Vol. 130, No. 4, 2012, pp. 879-885. doi:10.1542/peds.2011-3448

[11] Commission Européenne, "Proposition de Directive du Parlement Européen et du Conseil Relative au Rapprochement des Dispositions Législatives, Réglementaires et Administratives des États Membres en Matière de Fabrication, de Présentation et de Vente du Tabac et de Ses Produits," 2012

http://ec.europa.eu/health/tobacco/docs/com_2012_788_fr .pdf 